\title{
Preschoolers' Attention to Print During Shared Book Reading
}

\author{
Mary Ann Evans, Karen Williamson, and Tiffany Pursoo \\ University of Guelph
}

\begin{abstract}
Seventy-six children ages 3 to 5 were individually read two storybooks that had been specially formatted to contain salient printed words within the text, and illustrations and text on left or right-facing pages. The reader pointed to each word while reading to half of the children. After each book, children were asked to recognize elements of the illustrations and the specially formatted text elements from among a set of foils. Videotaped sessions were coded for the time children spent looking toward the pages with print versus illustrations. Analyses showed that the percentage of time looking at print was less than $2 \%$ in the no-pointing condition but increased with age. Pointing to the words increased print-looking time for all age groups and print target recognition for 4-year-olds. After controlling for receptive vocabulary, visual memory, and maturation associated with these scores, emergent orthography and letter-word identification predicted time looking at print and recognition of the print elements.
\end{abstract}

Storybook reading between parents and children has long been considered a valuable educational practice. In addition to enhancing a child's cognitive and emotional development increasing a child's interest in books, providing factual information about the world, and being an enjoyable activity, it is also assumed to enhance a child's oral and written language skills and later success in reading. Several studies have supported a positive association with language and literacy development as summarized in two meta-analytic reviews of the literature by Scarborough and Dobrich (1994) and Bus, van IJzendoorn, and Pellegrini (1995). In these reviews there was at least a modest correlation between the frequency of shared storybook reading in early childhood and outcome measures such as

Correspondence should be sent to Mary Ann Evans, Department of Psychology, University of Guelph, Guelph, Ontario, Canada, N1G 2W1. E-mail: evans@ @sy.uoguelph.ca 
language growth and reading achievement, with shared book reading estimated to account for about $8 \%$ of the variance.

The exact role that shared reading plays in the development of emergent literacy skills is, nonetheless, unclear given the multiple components of the interaction and of emergent literacy. Within emergent literacy skills, letter knowledge has been shown to be one of the strongest predictors of later reading success and is thought to be an important link between the various emergent literacy components (see Adams, 1990; Foulin, 2005; van Kleeck, 2003, for reviews.) However, the assertion that young children's knowledge of written language benefits from shared reading in the home has been questioned by longitudinal research findings emerging since the two aforementioned meta-analyses. Sénéchal, LeFevre, Thomas, and Daley (1998) examined the relative influence of shared book reading and parent-reported teaching activities in preschool/kindergarten on the oral and written language skills of Grade 1 and 2 children. Here the frequency of storybook reading predicted only oral language skills, whereas parent teaching predicted only written language skills. Similarly Evans, Shaw, and Bell (2000) found that after parental education and child age, nonverbal intelligence, and rapid automatized naming had been accounted for, the frequency of parent reported home activities directed to teaching letter names, sounds, and writing tasks predicted knowledge of letter names, letter sounds, and phonological awareness. The frequency of shared book reading did not, but rather was related to vocabulary development. Finally, Frijters, Barron, and Brunello (2000) found that among kindergarten prereaders, phonological awareness completely mediated the relationship they originally observed between frequency of shared book reading and knowledge of letter names and sounds, but the frequency of home reading activities showed a direct relationship to vocabulary. Overall, these studies suggest that, when considering the different components of shared book reading with young children, the novel vocabulary of storybooks, different sentence structures, and broad and imaginative content may foster semantic development, but the print from which the stories are read may not enhance the development of written language skill.

Most recently, Evans and Saint-Aubin (2005) and Justice, Skibbe, Canning, and Lankford (2005) employed an eye-tracking methodology to determine the extent to which 4- and 5-year-old children actually looked at the print in storybooks while being read books with pictures accompanying the text. Their findings were remarkably similar, showing that children infrequently fixated the print. The duration of print-directed eye fixations was less than $6 \%$ of children's fixation time on the book, and less than $5 \mathrm{sec}$ across the roughly $2 \mathrm{~min}$ of shared reading. This was true for each of a variety of short storybooks, some of which embedded print within the illustrations or contained large, decorated, colorful print. These laboratory findings support previous home observations of comments made during shared book reading showing that children rarely comment on print (e.g., Shapiro, Anderson, \& Anderson, 1997; van Kleeck, 2003; Yaden, Smolkin, \& Conlon, 
1993). Specifically, in a small descriptive study in which 4-year-old children's shared storybook sessions were recorded weekly for a 1-year period, Yaden et al. found that spontaneous questions asked by children were least likely to be about the graphic form of text (e.g., letters, punctuation, printed word arrays) in favor of questions about the pictures, story meaning, and word meaning.

The advantage of studies using eye trackers is that they can document accurately where on the page a child is looking, but the methodology is not without drawbacks. The setup in a laboratory with the books displayed on a computer screen may be criticized by skeptics as being unnatural and thus unrepresentative of what happens when children interact with paper books. In addition it is not possible to calibrate the eye tracker with children younger than 4 , as they are unable to fixate on specified single points on the computer screen long enough for the calibration to be completed. Thus the studies by Evans and Saint-Aubin (2005) and Justice et al. (2005) could not include younger children and did not address how children's attention to print might change across the preschool years.

The smaller sample sizes of these studies also preclude examining what child characteristics might be associated with individual differences in attending to the print in storybooks. Yaden et al. (1993) noted that in their study there were a few children from the age of 3 who did ask several questions about the written words (e.g., "What does that say?" "Does that say please?"). They suggested that questions about graphic form at this young age may be because of the influence of other home activities or individual child variables. More recently de Jong and Bus (2002) examined how children interacted with an electronic book in which the words could be pronounced when clicked on and in which the text changed color as it was read. They reported that most children did not seem to pay much attention to the print, but children who had scored higher on preliminary tests of letter and word knowledge were more likely to explore the print-related options. However neither Yaden et al. nor de Jong and Bus controlled for maturation or other cognitive characteristics that might also drive this behavior.

The aforementioned studies also have not addressed whether the manner in which one reads to the child will alter attention to the print. Although several studies have shown that adults do not typically reference print when they read storybooks to children (Baker, Mackler, Sonnenschein, \& Serpell, 2001; Ezell \& Justice, 1998, 2000; Phillips \& McNaughton, 1990; Shapiro et al., 1997; van Kleeck, 1995), a series of studies by Justice and Ezell (Justice \& Ezell, 2000; Justice \& Ezell, 2002; Justice, Weber, Ezell, \& Bakeman, 2002) has shown that parents can be trained to increase print references. This was accomplished via videotapes modeling five print-referencing behaviors (comments, questions and requests about print, pointing to print, and tracking print with finger while reading). This training in turn appeared to improve 4-year-olds' understanding of the concept of a word and concepts about print (Justice \& Ezell, 2000), and print awareness, alphabet knowledge, and print recognition (Justice \& Ezell, 2002). However, 
because five behavioral strategies were employed, it is unclear exactly what aspects of the intervention facilitated the children's understanding. Thus we tested whether only pointing to the words would alter children's attention to the print through assigning participants to either a word-pointing condition in which the adult pointed to the text as she read it or a standard no-pointing condition. Because three age groups were used, differences in the effectiveness of this reading style at these different ages could be assessed.

\section{THIS STUDY}

In summary, the main goals of this study were to examine age changes in, individual differences in, and the effect of the adult pointing to the words on attention to print in children ages 3 to 5 during shared book reading. Such an examination thus moves beyond looking at the simple frequency of book reading to the nature of shared book reading and its effect. As Golden and Gerber (1990) noted, what both the parent and child bring to the storybook reading session and how the text is mediated define the event and, in turn, the potential benefits gained from the experience.

Children were read a paper storybook in their preschool, allowing for a wider sampling of preschoolers and a natural data-collection setting. Like Evans and Saint-Aubin (2005) and Justice et al. (2005), we also chose to use fictional storybooks, as they are the most common types of books read to children (Stahl, 2003; van Kleeck, 2003). It was felt that more information about children's behavior with fictional storybooks would be useful in understanding the influence that this popular genre may have on children's development. Selected words within the printed text were specially formatted to enhance their visual saliency.

Two methods of estimating attention to printed words were used. As did Evans and Saint-Aubin (2005) and Justice et al. (2005), we calculated the percentage of time children spent looking at the print of total time looking at the book while being read two books. To obtain an additional measure of attention to print, we also gave children a recognition task in which they were to pick out which cards portrayed the salient print displays and aspects of the illustrations that had been in these two storybooks. Thus both accuracy for the two types of targets (pictures and print) on the recognition task and looking times at print provided an indication of children's relative attention to elements of the print and illustrations in the book.

Finally, because prior research has suggested that young children with stronger letter and word recognition pay more attention to the print during shared storybook reading (de Jong \& Bus, 2002; Yaden et al., 1993), we assessed children's emergent print knowledge, letter-word identification, visual memory, and receptive vocabulary. This allowed for an examination of the relationship of children's existing print-related skills to attention to the print and memory for aspects of the print and illustrations after controlling for vocabulary and visual memory. 


\section{METHOD}

\section{Participants}

Participants were recruited from two community and two university-based day care centers in southwestern Ontario. Parent information letters, consent forms, and a questionnaire concerning demographics of the family and home literacy experiences of the children were sent home to all children at the day cares between 3 to 5 years of age. A total of 89 consent forms were completed and returned. Among these children were 3 who were not included in the study because of major exceptionalities that affected their cognitive development and 6 who completed the first testing session but were no longer attending the day care when the second session took place. After the data collection had been completed, 3 more children were deleted from the sample: 2 who were able to read more than eight words on a standardized word identification test, and 2 others whose scores on several measures were outliers within their respective age group. The final sample consisted of 76 children ( 38 girls and 38 boys) who ranged in age from 36 to 73 months at the first testing session.

The parent or guardian providing consent was asked to complete a questionnaire about the demographics of the family and home literacy environment. Five of the parents who consented to their child's participation in the study failed to return the questionnaire. Questionnaires from the remaining 71 parents indicated that the majority of the children were from middle-class to upper middle-class homes with well-educated parents, although 15 families reported a family income from less than $\$ 16,000$ to $\$ 40,000$ in Canadian dollars. All but $13 \%$ of mothers and $18 \%$ of fathers had obtained some form of postsecondary schooling, and approximately $30 \%$ had obtained a graduate degree. Data from Statistics Canada (2001a, 2001b) for these same variables for families in southwestern Ontario showed that the demographic characteristics of the sample were similar to the broader regional population. Within the questionnaires parents reported on whether they pointed to the print during shared book reading rarely, on a few pages, on most pages, or on almost all pages. Parents reported spending an average of $172 \mathrm{~min}$ of shared book reading each week, with $17 \%$ of parents rarely pointing to the text, $42 \%$ to text on a few pages, $25 \%$ to text on most pages and $9 \%$ to text on almost all pages. There was no significant difference between age groups in pointing to text or in time spent reading to the child, and correlations between these parent variables with children's looking time and recognition scores in the results below were all less than .18 and not significant.

\section{Materials}

Tests of individual ability. The Letter-Word Identification subtest from the Woodcock-Johnson III Tests of Achievement (Woodcock, McGrew, \& Mather, 
2001) was used as both a reading ability screening test and a measure of beginning orthographic knowledge. In this subtest, children are asked to identify and name uppercase and lowercase letters, point to the written form of spoken words, and read printed words. To limit the study to nonreaders and barely beginning readers, children who were able to read more than eight words on this subtest were not included in the study. The subtest has demonstrated good reliability, with test-retest reliability coefficients ranging from .87 to .96 for children ages 3 to 5 years (Woodcock et al., 2001).

A measure of emergent orthography knowledge developed by Levy, Gong, Hessels, Evans, and Jared (2006) was used to assess the children's understanding of English print and spelling conventions. In this test, children see pairs of printed items and are asked, "Which one would your mommy or teacher be able to read?" Items tap 13 dimensions of orthographic characteristics, each having 10 pairs of stimuli for the child to look at. In each pair, one is written in conventional English (lowercase letters) and the other in a variant of the word that differs in form on the basis of 1 of the 13 dimensions. Levy et al. reported that development between the ages of 4 and 5 years was seen on 6 of the 13 dimensions tapped by the items, these 6 being administered in our study. In addition, reliability as assessed by correlating stimuli using words versus sentences was .92. In our study, children saw pairs of words differing according to linearity of letters, multiplicity of letters, spacing of letters, scribbles versus letters, letterlike forms versus nonletters, and pictures versus letters. The 60 items were arranged such that all of the 6 dimensions were dispersed throughout the items. The starting point within the items was randomly chosen so that different items appeared earlier or later in the test session to control for the effects of fatigue or any order effects.

Receptive language abilities were measured using the Peabody Picture Vocabulary Test-III (Dunn \& Dunn, 1997). For each item, the child is asked to point to the one of four black-and-white illustrations that best represents the meaning of the word presented orally by the experimenter. The reliability of this test is very good, with split-half internal consistency coefficients ranging from .93 to .95 , and a test-retest reliability coefficient of .92 for children ages 3 to 5 years, and scores highly correlate with the full Wechsler Intelligence Scale for Children-III and Verbal IQ composite within it (Wechsler, 1991).

Finally, visual memory skills were assessed with the Visual Recognition subtest of the British Ability Scales (Elliot, 1983). In this subtest, children are shown a black-and-white drawing of one or more objects for $5 \mathrm{sec}$. They are then asked to find the same object(s) out of a group containing distracter objects. There are 17 items in total. The Hoyt reliability coefficient for this subtest ranges from .84 to .67 for children ages 3 to 5 years.

Home Literacy Experiences Questionnaire. A Home Literacy Experiences Questionnaire (Evans, Levy, \& Jared, 2001; Levy et al., 2006) was used to 
gather information about sample demographics, home literacy practices, languages spoken in the home, and any developmental concerns.

Storybooks. Two large picture books were created for use in this research study. The story and accompanying pictures in each book generally followed that of already-published children's books Meg and Mog (Nicoll \& Pienkowski, 1972) and Harriet Reads Signs and More Signs (Maestro \& Maestro, 1981). These books were chosen because the storylines and language were appropriate for young children and the illustrations contained several examples of print that had been made salient by certain stylized elements. For example, the Harriet book had street signs on every page that were highlighted by the narrative, and Meg and Mog contained various elements of print in large nonstandard fonts. The format of the books was modified using a photo editing computer program and a high-resolution color printer to conform to the characteristics presented next that would allow for the calculation of relative looking time at print versus illustrations and the use of the recognition cards.

First, each page was printed to measure a larger size $-28 \mathrm{~cm}$ (width) $\times 22 \mathrm{~cm}$ (height) - with the print of the story always contained on one page and the illustrations spanning the other with a 2 to $3 \mathrm{~cm}$ white border around the periphery. (The exception to this was the cover page containing both print and illustration.) Thus any print embedded in the original pictures was removed. This format was necessary so that looking time at print versus illustrations could be calculated according to which direction or side of the book the child turned her or his eyes toward. Second, the side of the open book in which the print appeared was varied to control for the possibility that a child might simply prefer to look at one side of the book. On pages with print, the print appeared in 24-point font in black on a white background with an average of three lines of print and 20 words per page. Third, additional parts of the print throughout the book were made distinctive in size, shape, or form (or a combination of these) to have sufficient print targets to test for recognition. Making some words visually salient through distinctive stylized or "picturelike" print was necessary given that the children were nonreaders who could not be expected to recognize words in conventional font. Finally each book was modified to contain 12 pages of print and illustrations. To ensure that all of these modifications did not affect either the child's comprehension or enjoyment of the story, the text was also slightly modified. The uninterrupted reading time of each book was approximately $2.5 \mathrm{~min}$.

Recognition cards. Twenty-four $10 \mathrm{~cm} \times 7.5 \mathrm{~cm}$ recognition cards were created for each book. Half of the cards contained targets and half contained foils. All targets appeared only once throughout the book, and all foils were distinct from all pictures or stylized words appearing anywhere within the book. Targets and 
foils were presented in pairs, and the children were asked to select which one appeared in the book.

Six of these cards contained reproductions or targets of the stylized print (one word or two consecutive words) appearing in the book, for example, a word in a large distinctive font or a word that contained iconic properties such as a WALK sign within a yellow box. Several of these words were accompanied by a change in voice quality during the reading of the story. For example, the words Whoo, whoo were printed in large slanted bubblelike letters in the text and were read with a whooing sound such as that made by an owl. Six other cards displayed print foils that were not in the book but were equally and differently stylized from the targets. Similarly for the illustrations, six cards displayed target elements of illustrations from the book. These picture targets were named neither in the story nor in central elements of the illustrations. The purpose of these criteria was to lessen the possibility that the child would correctly choose an illustration target by remembering hearing the corresponding word, as opposed to visually attending to the illustrations. Their six corresponding foils were illustrations that were not in the book. These foils were chosen to be relatively similar in style and/or content to the target, so as to be consistent with the design of the book but distinct enough to allow for differential recognition. For example, a picture of a small yellow ghost appearing in the background was used as a target illustration, and its foil was a yellow goblin from another book by the same illustrator.

\section{Procedure}

Each child was seen individually and participated in two sessions with one of the authors. Both of these sessions took place in a quiet room in the child's day care setting. The time between the first and second sessions for any given child varied from 2 weeks to 3 months depending on scheduling considerations and child attendance. All storybook reading sessions were videotaped with a digital video camera. The taping typically occurred at a distance of approximately $2 \mathrm{~m}$ from the dyad, with some variation depending on the space constraints and configuration of the different day care centers. The zoom feature of the video camera was used to obtain a closer view of the child's gaze during the reading sessions.

In the first session, the child was administered the four measures of individual ability. Each test was administered and scored using the standard procedures outlined in the manual, with the entire session typically lasting between 25 and 40 min. The order of administration was varied depending on the child's attention level and comfort with the testing situation, so as to attain the optimal results from each child. With older children, the Letter-Word identification subtest was typically administered first to ensure that the child was eligible to continue as a participant in the study. 
In the second session the participants were read the two books and tested on their recognition of print and picture targets. Prior to the session, each child was randomly assigned to both a book order (Meg and Mog first vs. Harriet first) and word pointing condition (pointing vs. no pointing) by flipping a coin. In an effort to obtain an equal number of children in each book order and word-pointing condition within each age group (3-, 4-, and 5-year-olds) approximately the last 10 children in this process were assigned a particular condition. If word pointing was assigned to a given child, the experimenter followed the words with her finger as she read both books to the child.

Storybook reading. Before the stories were read, children were told, "I am going to read some stories to you now. After we're done reading, we will talk a little bit about the book and you will have a chance to see some of the things that were in the book again." Each storybook was read to the child by the experimenter while sitting by the child's side. The book was held by the experimenter at an angle of approximately $45^{\circ}$ and positioned so that the spine of the book was directly in front of the child and so that the child's face was not covered by the book, but also so that he or she was not looking down. Keeping the spine of the book directly at the midline of the child was done so that the side of the book that the child was looking at could later be coded.

The same person read both books to every child at a consistent speed with similar expression and tone. After each page was turned, the experimenter waited $2 \mathrm{sec}$ before reading the text and $2 \mathrm{sec}$ after finishing the text before turning the page. If the child asked a question, made a comment, or interacted with the book, the experimenter responded accordingly with a phatic remark or simple answer. For example, if the child said, "Look at that dog. Isn't he funny?" while pointing to the picture, the reader made a response such as "Yes, he is," and returned to the story where she left off. During the very few cases where a child talked in excess about something off-topic, the reader closed the book, tried to cut the conversation short, and then continued on with the story. The most common comments children made during reading were simply pointing out and naming objects (e.g., "A witch!") that did not require responses and did not interfere with the flow of the story. There was a short break between the two books in which the reader made general remarks such as "That was a pretty neat book," and the child chose a sticker.

Presentation of recognition cards. The 12 pairs of recognition cards corresponding to each book were presented to the child immediately after the story had been completed. This task took place at a table with the child and experimenter side by side. If a table was not readily available, the cards were held up for the child to look at. The sets of target and foil cards were shuffled for each child so that they were presented in a random order. Before any cards were presented, the following directions were given: 
Now we are going to play a little game to see how much you can remember about the book. I am going to show you some cards (while showing the cards quickly) that have different things on them. I am going to show you two of these cards (while laying down the fist pair). One of these things was something that was in the book, and one of them wasn't. I want you to show me which one was in the book.

If the child did not respond to the instructions, or looked confused, encouragement and/or clarifications were given. On subsequent presentations of pairs, the instructions given were shortened or eliminated if the child understood the task. On any given pair children were also encouraged to guess if they said they did not know. This same procedure was repeated after the second book had been read using the 12 pairs corresponding to that book. The session typically lasted 15 to $20 \mathrm{~min}$. After the two books had been read and the cards presented, the child was given another sticker and thanked for his or her participation.

For each pair of presented recognition cards, a correct choice of the target was scored 1 point. Therefore, for each book the child could score a maximum of 6 points for the cards containing print and 6 points for the cards containing illustrations. Scores for both books were combined for the measure of print target recognition and illustration target recognition for a maximum of 12 points each.

\section{Video Coding}

The videotapes of the storybook reading sessions were coded with the computer program FOCAL (Roberts, 2003). The videos were watched in slow motion (three times slower than real time) and coded for whether the child was (a) looking at the page with text on it, (b) looking at the page with illustrations on it, (c) not looking at the book at all, or (d) not looking at anything in particular because the pages were being turned. By using the points in time when a shift of focus occurred, the computer program calculated durations. The total durations for each of these four categories were separately summed, and a percentage of the time spent looking at the print was calculated by dividing the total amount of print-looking time by the total amount of time spent looking at the book. Therefore, percentage of printlooking time $=[a /(a+b)] \times 100$. This percentage was used so that the measure of print-looking time would not be influenced by fluctuations in the total amount of time taken to read the book. An average of the calculated print-looking times for both of the books was used (unless specified otherwise) and is referred to as simply total print-looking time.

Interrater reliability of video coding. One of the authors recoded the reading sessions of 13 children ( 26 books in total) using the same procedure. The resulting Pearson correlation between the total print-looking times of both coders was $.995(p<.001)$. A matched-samples $t$ test that compared the degree of 
difference between the total print-looking time scores of the two coders was nonsignificant, $t(12)=.19, p>.05$ ( $M$ and $S D$ for Coder A vs. Coder B were 9.75 and 10.44 vs. 9.69 and 10.75). Finally, to determine the actual amount of variation in the coding between the two, the difference between each of the print-looking time percentages was calculated for all 26 observations. The average difference between coders in calculated percentage of print-looking time for each observation was found to be less than $5 \%$.

\section{RESULTS}

\section{Data Cleansing}

Prior to analysis, the data were checked for accuracy of scoring, coding, and data entry, and distributions of the dependent measures at all levels of the independent variables were examined. Two univariate outliers for total print-looking time with scores more than $3.29 S D$ higher than the mean were replaced with a score that was 1 unit larger than the next most extreme scores for that age group and condition for that variable (Tabachnick \& Fidell, 1996). With respect to the distributions of print-looking time, and print and illustration target recognition, scores for both recognition card variables were normally distributed, but the total print-looking time variable was positively skewed and/or kurtotic for some age groups in the no-pointing condition. Further, Kolmogorov-Simirnov and Shapiro-Wilk tests of normality for print-looking time were significant for several levels of the age group and pointing conditions, and the variance of the total print-looking time in the pointing group was more than 8 times larger than that of the no-pointing group. Thus total print-looking time was transformed using a square root transformation that resolved the aforementioned problems. In the analyses, the transformed print-looking time scores were used. Because the original values of total percentage time spent looking at the print are the scores that are meaningful, the untransformed means are be reported in the text, tables, and figures (Howell, 1997).

\section{Preliminary Analyses}

Two-tailed, independent samples $t$ tests revealed no significant difference between boys and girls on total print-looking time, $t(74)=-.76, p>.05(M$ and $S D=8.30$ and 7.04 for boys vs. 11.24 and 11.83 for girls, respectively); print target recognition, $t(74)=-.76, p>.05$ ( $M$ and $S D=6.55$ and 2.05 for boys vs. 7.47 and 2.49 for girls, respectively); or illustration target recognition, $t(74)=-1.32, p>.05$ ( $M$ and $S D=8.53$ and 1.86 for boys vs. 9.13 and 2.12 for girls, respectively). Thus gender was not considered in the subsequent analyses. In addition, a two-tailed matched samples $t$ test using transformed print-looking times showed that the percentage of 
print-looking time between the two books did not differ, $t(75)=1.89, p>.05(M$ and $S D=8.76$ and 9.62 for Harriet vs. 10.89 and 12.28 for Meg \& Mog using untransformed scores).

The duration of the storybook reading sessions varied because of slight fluctuations in reading speed, time spent turning pages, and the children's spontaneous comments but averaged $2 \min 35$ seconds. The children were typically very attentive. Not looking at the book during the reading sessions averaged just $2.56 \%$ of the time, and there was no difference in this index of inattention to the book between age group or between pointing conditions. Even the 3-year-olds look elsewhere than at the book just $3 \%$ of the time.

\section{Age Changes in Attention to the Book Elements}

To examine attention to the book, Age (3-, 4-, and 5-year-olds) $\times$ Condition (pointing or no pointing) factorial analyses of variance (ANOVAs) were conducted on total print-looking time, total print target recognition, and total illustration target recognition.

Total print-looking time. The total times looking toward the print as a function of age of child and condition are shown in Figure 1, where it can be seen that
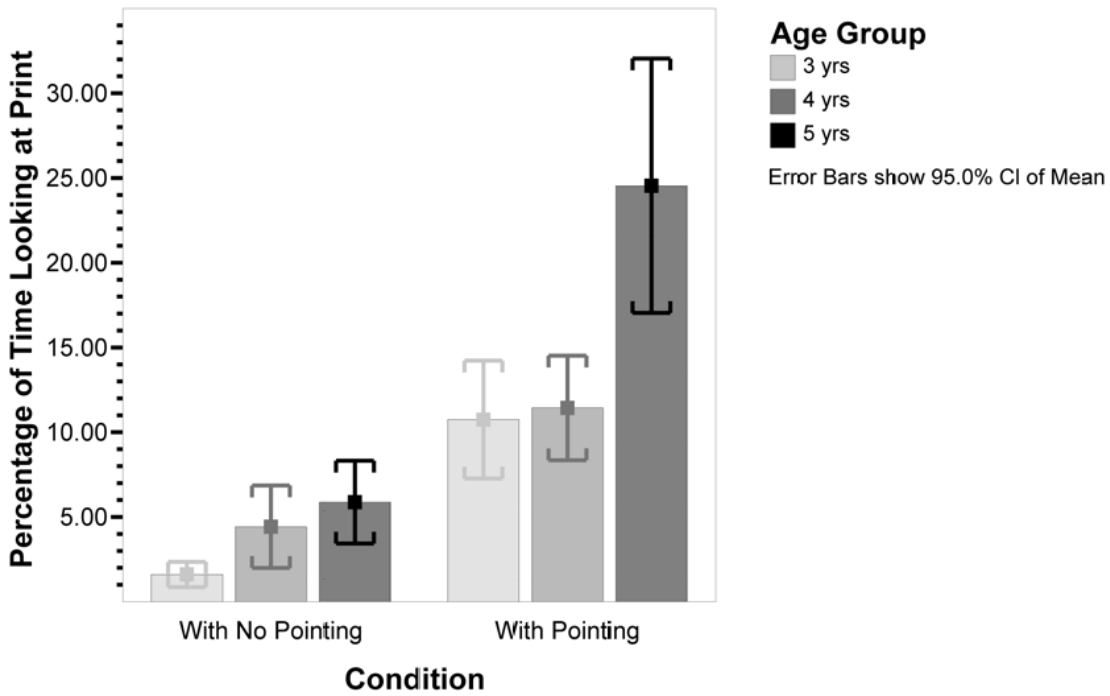

FIGURE 1 Mean percentage (and 95\% confidence intervals) of print looking time as a function of age and condition. Note. Means presented are untransformed scores. Square-root transformations were used in the statistical tests. 
looking time increased with age and was greater when the words are pointed to. The ANOVA confirmed that there was a significant main effect of age group, $F(2$, $70)=15.18, p<.001, \eta^{2}=.30$. Fisher's Least Significant Difference (LSD) test showed that there were significant differences in print-looking time between all three age groups. The 5-year-olds spent a higher percentage of time looking at print than the 4-year-olds, $t(70)=.95, p<.001$, and 4-year-olds than the 3-yearolds, $t(70)=.52, p<.05$. There was also a main effect of condition, $F(1,70)=$ $94.55, p<.001, \eta^{2}=.58$. Children in the condition in which the words had been pointed to showed a higher percentage of print-looking time $(M=15.50$ vs. $M=$ $3.80)$. There was no significant interaction between these two variables, $F(2,70)=$ $2.25, p>.05$.

As was expected from previous research findings, children in all of the age groups spent a greater percentage of time looking at the illustrations in the books compared to the print. Although there was variation between the age and condition groups, the average percentage of print-looking time was less than $25 \%$ for children of all ages in the condition in which the words were pointed to, and less that $6 \%$ in the condition in which words were not pointed to.

Print target recognition. Figure 2 presents the average number of print targets recognized by children in the different ages and two conditions. Again older

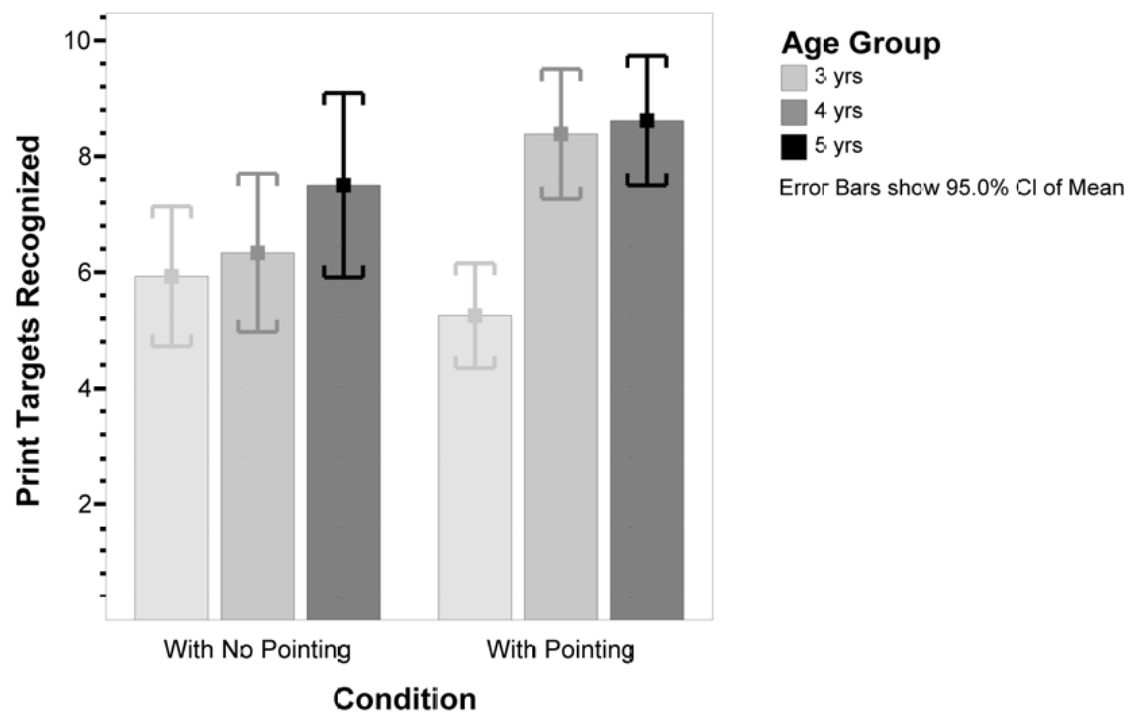

FIGURE 2 Mean number of print targets recognized (and 95\% confidence intervals) as a function of age and condition. Note. A score of 6 of the 12 forced choice items is a chance level of responding. 
children appear more accurate than younger ones. The ANOVA confirmed that there was a significant main effect for age on total print target recognition, $F(2,70)$ $=10.28, p<.001, \eta^{2}=.23$, but no effect for pointing condition, $F(1,70)=3.25, p>$ .05 Fisher's LSD tests showed that there were significant differences between the 3 - and 4-year-olds, $t(70)=-1.78, p<.01$, and the 3 - and 5-year-olds, $t(70)=-2.46$, $p<.001$, but not the 4 - and 5-year-olds, $t(70)=-.68, p>.05$. Thus the two older age groups were able to recognize more aspects of print from the book than the 3-year-olds.

Figure 2 also shows that pointing to the words did not improve the performance of the 3-year-olds who remained at chance level. To determine whether it affected the older children, two independent samples $t$ tests were conducted with the alpha level set at .025 to protect against inflated error rates. The results showed that pointing to the words significantly improved print-target recognition for the 4-year-olds, $t(23)=2.57, p<.025$, but not for the 5-year-olds, $t(23)=1.27, p>$ .025 . These simple differences should be interpreted cautiously, however, as the number of participants in these analyses was just 12 to 13 children.

Illustration target recognition. Figure 3 presents data for children' accuracy recognizing aspects of the illustrations by age group and condition. It can be seen that children faired better on this task than in recognizing print target, that older

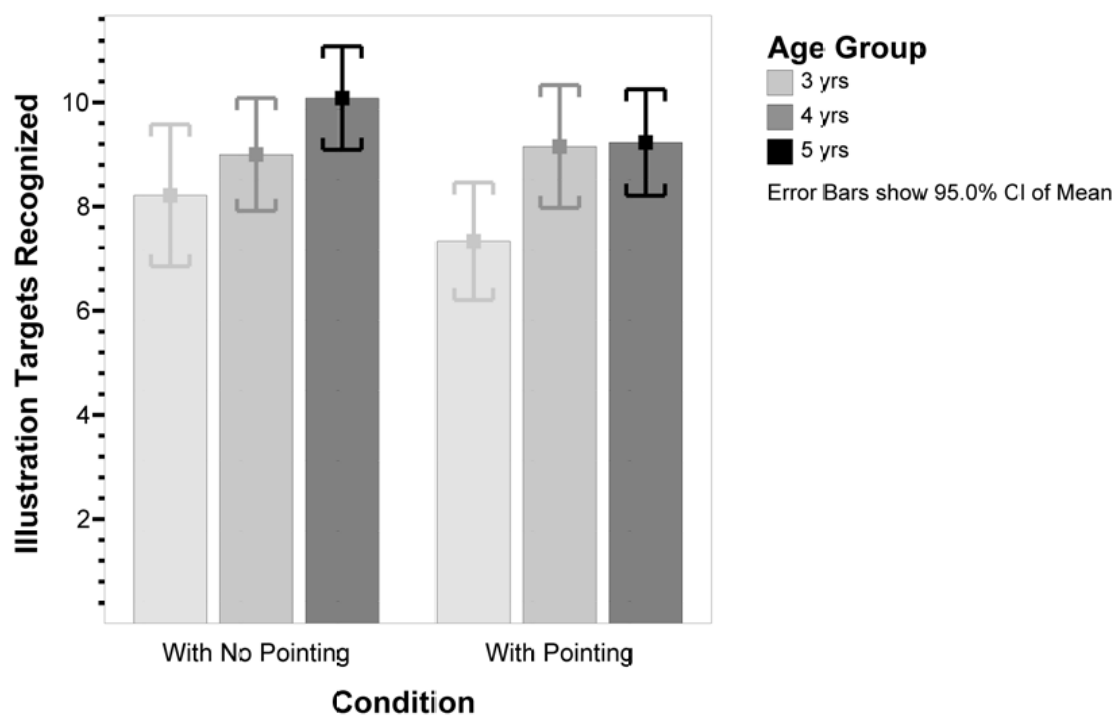

FIGURE 3 Mean number of illustration targets recognized (and 95\% confidence intervals) as a function of age and condition. Note. A score of 6 of the 12 forced choice items is a chance level of responding. 
children achieved higher scores than younger children, and that pointing to the words did not affect children's recognition accuracy. An ANOVA confirmed that there was a main effect for age on illustration target recognition, $F(2,70)=6.75, p$ $<.01, \eta^{2}=.16$. Fisher's LSD tests showed that there was a significant difference in illustration recognition accuracy between 3- and 4- year-olds, $t(70)=-1.27, p<$ .05 , and 3- and 5- year-olds, $t(70)=-1.83, p<.01$. The accuracy of $4-$ and 5 -year-olds did not differ, $t(70)=-.56, p>.05$. There was no significant effect for condition, $F(1,70)=1.50, p>.05$. There was also no significant interaction between the two variables, $F(2,70)=.62, p>.05$. Thus pointing to the text did not detract from children's attention to the pictures.

Print and illustration target recognition as compared to chance. Twotailed, one sample $t$ tests were conducted to see whether children's performances on the two recognition tasks were significantly different from chance (a score of 6). The 3-year-olds' average score on the print recognition task was not above chance levels, $t(25)=-1.08, p>.05(M=5.62, S D=1.81)$, but it was for the illustration targets, $t(25)=4.35, p<.001(M=7.81, S D=2.12)$. For 4-year-olds, their performance on both print targets, $t(24)=3.16, p<.05$, and illustration targets, $t(24)=8.56, p<.001$, was better than chance ( $M$ and $S D=7.49$ and 2.22 for print targets, and 9.08 and 1.80 for illustration targets, respectively). Because the 5-year-olds' scores were higher than the other two groups, their performance on these tasks was obviously higher than chance as well. On average they recognized $8.08(S D=2.22)$ print targets and $9.64(S D=1.66)$ illustration targets.

\section{The Relationship of Individual Abilities to Attention to Print and Pictures}

Means and standard deviations for the individual measures of cognitive abilities and skills (Peabody Picture Vocabulary Test, visual recognition, emergent orthog-

TABLE 1

Mean Scores (and Standard Deviations) of Measures of Individual Ability in Raw Scores

\begin{tabular}{lccccc}
\hline Age Group & $n$ & $\begin{array}{c}\text { Peabody } \\
\text { Vocabulary }\end{array}$ & $\begin{array}{c}\text { Visual } \\
\text { Recognition }\end{array}$ & $\begin{array}{c}\text { Emergent } \\
\text { Orthography }\end{array}$ & $\begin{array}{c}\text { Letter-Word } \\
\text { Identification }\end{array}$ \\
\hline 3-year-olds & 24 & 57.54 & 6.50 & 38.17 & 6.92 \\
& & $(18.43)$ & $(3.20)$ & $(13.69)$ & $(4.02)$ \\
4-year-olds & 24 & 72.12 & 8.29 & 50.25 & 9.37 \\
& & $(10.33)$ & $(2.14)$ & $(12.59)$ & $(3.29)$ \\
5-year-olds & 23 & 92.00 & 10.96 & 58.52 & 14.04 \\
& & $(19.27)$ & $(2.20)$ & $(4.46)$ & $(4.15)$ \\
\hline
\end{tabular}


raphy, letter-word identification) are displayed in Table 1 . Three of the 35 children in the no-pointing condition and 2 of those in the pointing condition were not included here and in the forthcoming analyses because of scores deemed invalid. Four of these 5 children did not comply with the procedure on the emergent orthography subtest resulting in invalid scores, and the other spoke English as a second language, creating an outlier score. Thus the sample size here was 71 .

The 3-year-olds were typically able to name some letters (about four or five) but had a poorly developed understanding of the orthographic properties of words and were nonreaders. In contrast, the 5-year-olds had no difficulty identifying displays that appeared in valid orthographic form as words and made few mistakes on the emergent orthography measure. Although most of the children in this age group could identify and name the uppercase and lowercase letters presented, they could read only a few basic words.

The previous ANOVAs showed age effects on time looking at print, number of print targets recognized, and number of picture targets recognized. To examine the predictors of age-related individual differences in these measures, a series of three hierarchical regression analyses was conducted with receptive vocabulary and visual memory entered at the first step and emergent orthography and letter-word identification at the second step. Because the amount of time looking toward the print was positively correlated with accuracy in recognizing print targets, print-looking time was added at a third step in the prediction of number of print targets recognized. Intercorrelations between the variables appear in Table 2 , showing that all scores were positively correlated with the exception that number of picture targets recognized was uncorrelated with letter-word identification scores or the amount of time looking at the print. Table 3 summarizes the regressions.

TABLE 2

Intercorrelation of Variables

\begin{tabular}{lccccccc}
\hline Variable & $\begin{array}{c}\text { PPVT } \\
\text { Vocab }\end{array}$ & $\begin{array}{c}\text { Visual } \\
\text { Recog. }\end{array}$ & $\begin{array}{c}\text { Emergent } \\
\text { Ortho. }\end{array}$ & $\begin{array}{c}\text { Letter- } \\
\text { Word ID }\end{array}$ & $\begin{array}{c}\text { Print } \\
\text { Looking }\end{array}$ & $\begin{array}{c}\text { Print } \\
\text { Targets }\end{array}$ & $\begin{array}{c}\text { Picture } \\
\text { Target }\end{array}$ \\
\hline PPVT Vocab & - & & & & & \\
Visual recog. & $.52^{* * *}$ & - & & & & \\
Emergent ortho. & $.49^{* * *}$ & $.38^{* * *}$ & - & & & & \\
Letter-word ID & $.65^{* * *}$ & $.44^{* * *}$ & $.52^{* * *}$ & - & & & \\
Print looking & $.28^{* *}$ & $.26^{*}$ & $.25^{*}$ & $.42^{* * * *}$ & - & & \\
Print targets & $.32^{* *}$ & $.38^{* * *}$ & $.43^{* * *}$ & $.30^{* * *}$ & $.48^{* * *}$ & - & \\
Picture targets & $.48^{* * *}$ & $.34^{* * *}$ & $.33^{* *}$ & .19 & -.05 & $.34^{* * *}$ & - \\
Age & $.74 * * *$ & $.62^{* * *}$ & $.58^{* * *}$ & $.63^{* * *}$ & $.39^{* * *}$ & $.46^{* * *}$ & $.43^{* * *}$ \\
\hline
\end{tabular}

Note. $\quad$ PPVT Vocab $=$ Peabody Picture Vocabulary Test $;$ recog. $=$ recognition; ortho. $=$ orthography; ID = identification.

$* p<.05 . * * p<.01 . * * * p<.001$. 
TABLE 3

Summary of Regressions Predicting Attention to Print and Illustrations

\begin{tabular}{|c|c|c|c|c|c|}
\hline Dependent Variable & Predictor & $\Delta R^{2}$ & $p$ & Total $R^{2}$ & Final Beta \\
\hline Print-looking time & & & & .20 & \\
\hline \multirow[t]{2}{*}{ Step 1} & PPVT & .10 & .027 & & -.07 \\
\hline & Visual memory & & & & .12 \\
\hline \multirow[t]{2}{*}{ Step 2} & Emergent orthography & .10 & .024 & & .10 \\
\hline & Letter-word ID & & & & .37 \\
\hline Print target recognition & & & & .40 & \\
\hline \multirow[t]{2}{*}{ Step 1} & PPVT & .16 & .002 & & .05 \\
\hline & Visual memory & & & & .19 \\
\hline \multirow[t]{2}{*}{ Step 2} & Emergent orthography & .08 & .040 & & .27 \\
\hline & Letter-word ID & & & & -.14 \\
\hline Step 3 & Print-looking time & .16 & .001 & & .45 \\
\hline Picture target recognition & & & & .29 & \\
\hline \multirow[t]{2}{*}{ Step 1} & PPVT & .24 & .001 & & .51 \\
\hline & Visual memory & & & & .14 \\
\hline \multirow[t]{2}{*}{ Step 2} & Emergent orthography & .05 & .100 & & .17 \\
\hline & Letter-word ID & & & & -.29 \\
\hline
\end{tabular}

Note. $\quad$ PPVT $=$ Peabody Picture Vocabulary Test; ID = identification.

The first regressions revealed that receptive vocabulary and visual memory accounted for $10 \%$ of the variance on the amount of time that children looked at the print. After accounting for these two cognitive abilities, print knowledge accounted for an additional $10 \%$ of the variance.

With respect to the recall of visual aspects of the books, receptive vocabulary and visual memory accounted for $24 \%$ of the variance in the extent to which children recognized the illustration targets. Emergent orthography and letter-word identification scores accounted for a nonsignificant $5 \%$ additional variance. The results for print target recognition were different. Here vocabulary and visual memory accounted for $16 \%$ of the variance on the first step, and emergent orthography and letter-word identification scores added a further $8 \%$ on the second step. As the final step print-looking time added an additional $16 \%$.

\section{DISCUSSION}

The main purpose of this study was to examine children's attention to the printed elements of storybooks being read to them by an adult, and whether their attention is directed toward the text by the adult pointing to each word. This study used two indexes of attention to print_-amount of time looking toward the printed pages and accuracy in recognizing aspects of the print that had been made visually salient via unusual fonts and colors. The percentage of print-looking time predicted $16 \%$ of 
the variance in print target recognition after variance accounted for by receptive vocabulary, visual memory, emergent orthography, word-identification, and maturation associated with those scores. In contrast, there was no relationship between print-looking time and performance on the illustration recognition cards. Further, overall target recognition scores were higher for the illustration cards than for the print cards at all age levels. Therefore, the print recognition cards can be considered a second window on attention to print during the reading sessions in that items displayed could not be recalled if they had not been initially attended to.

\section{Looking Time at Print Versus Illustrations}

Despite the fact that our study used a less technical method of calculating the amount of time that children look at print during shared storybook reading than the eye-tracking studies of Evans and Saint-Aubin (2005) and Justice et al. (2005), it replicated their findings. Children in all three age groups spent a substantially greater percentage of time looking at the illustrations than the text. Children's eyes were turned toward the pages with text less than $4 \%$ of the time across all three age groups when the words were not pointed to. This equaled roughly $6 \mathrm{sec}$ of print-looking time over a $2 \frac{1}{2}$-min reading session. Although one cannot infer how much time looking at print is necessary to aid in the development of print skills or concepts, these low percentages provide a clue for why shared reading in this age group has been shown to be less directly related to print knowledge than to language knowledge outcomes (Evans et al., 2000; Frijters et al., 2000; Sénéchal et al., 1998). Put simply, young children look little at the printed pages.

\section{Age Differences in Print Attention}

Although the extent to which children looked toward the print remained small across the three age groups, it nonetheless increased from 3 to 5 years of age. Mason (1980) and Lomax and McGee (1987) suggested that children become more interested in interpreting printed words in their environment once they have developed some rudimentary emergent literacy skills such as phonemic awareness and letter-name knowledge. Similarly de Jong and Bus (2002) and Yaden et al. (1993) noted that children ask more questions about text during shared book reading when they have developed a base of knowledge about letters and print concepts. Support for this position was shown by the regression in our study predicting print-looking time. After accounting for $10 \%$ of the variance predicted by receptive vocabulary and visual memory, children's emergent orthography and letter-word identification knowledge significantly predicted additional variance in even the small extent to which children looked toward the print. Thus the observed increase in printlooking time with age appears to be partly because of children's developing emer- 
gent literacy skills, which show considerable growth from 3 to 5 years of age (e.g., Adams, 1990; Hiebert, 1981; Lomax \& McGee, 1987; Mason, 1980).

Children's performance on the print recognition task also increased with age, which suggests that older children not only looked more at the text but also attended to details within the printed text. The 3-year-olds' performance on this task was significantly poorer than the 4- and 5-year- olds' and reflected chance levels of responding. In contrast children in all three groups performed at better than chance on the illustration recognition task. Thus the poor performance of the youngest children in recognizing the print targets was not likely because of a failure to understand the task.

Although looking at the text would be a necessary condition for recalling it, it does not appear to have been sufficient. Rather, the regression showed that children's print knowledge predicted $8 \%$ of the variance in print target recognition, over and above the $16 \%$ accounted for by receptive vocabulary and visual memory. An understanding of the visual features that characterize written words appears to assist with visually processing or selectively processing the print targets.

\section{Effect of Pointing to Text}

Children at all three age groups in the pointing condition spent a significantly greater percentage of time looking at the print than those in the control condition, with pointing exerting a medium effect $\left(\eta^{2}=.58\right)$. However pointing to the words did not similarly influence print target recognition across all age groups. It did not improve the performance of the 3-year-olds who remained at floor on the print recognition task or that of 5-year-olds who initially were better than chance. However having an adult reader point to the text while reading enhanced 4-year-olds memory for print elements. This suggests that pointing to the text may be an effective strategy for increasing the amount of attention paid to print during shared storybook reading when children are developing preliminary concepts about the shape of printed words. At the least, in combination with other print referencing strategies, it has been shown to increase print knowledge (Justice \& Ezell, 2002). However only cautious enthusiasm for pointing to text during shared book reading as a means in itself to enhance attention to print in trade storybooks is voiced at this point, given the novelty that pointing may have had for many of the children. Although Apel, Wolter and Masterson (2006) found that pointing to words resulted in 5 -year-olds learning orthographic information about the words, the particular books they used were atypical: The words were repeated four times and appeared in distinctive 32-point font.

\section{Characteristics of Books that May Increase Attention to Print}

Across all ages, children's accuracy ranged from $46 \%$ to $75 \%$ for the print targets and 59\% to 92\% for the illustration targets. Examination of the children's relative 
rate of accuracy on the print items provided some clues as to the aspects of print that may have been more memorable for children. Children most accurately recognized print targets that contained distinct shapes and the most iconic properties. For example, the highest accuracy rate $(75 \%)$ for the print targets was a sign shaped like an arrow that said "Detour." Past research suggests that children may be drawn to icons and stylized elements of print (de Jong \& Bus, 2002; Yaden et al., 1993), but Evans and Saint-Aubin (2005) did not observe increased attention to print when it appeared in speech bubbles within the illustration or in a large decorated font. The children also did well on print targets that had been read in a unique tone of voice. Some children spontaneously pointed to and imitated the sounds after the adult reader and remembered what spoken words went with this stylized print on the recognition task, such as a child who exclaimed, "I remember seeing this one. It says Whoo Whoo!" This print target, written in bubblelike letters, was recognized accurately on average $67 \%$ of the time. When combined with finger pointing and dramatized tones of voice, such repeated words with simple sound structures may be easier for children to make a correspondence between print and speech, if only in a logographic fashion.

\section{Limitations and Directions for Future Research}

First although reported incomes and education levels were comparable to families in southern Ontario (Statistics Canada, 2001a, 2001b), the majority of the children in this study came from homes with well-educated parents, and the findings may not generalize to other populations. Second, the sample size when split between three age groups and two conditions is small, and as such the results can only to interpreted cautiously.

Third, this study entailed only one reading of each book but in the home, children's books are typically read multiple times (de Jong \& Bus, 2002). With repeated readings of the same book and increased story familiarity, children's attention to print and illustrations might shift. In their study, de Jong and Bus (2002) reported that 4- to 6-year-old children pointed at the text and attempted to read more words when asked to read a familiar versus an unfamiliar book. These authors suggested that the repeated readings produced some internalization of the graphic features of the text despite the fact that the children could not read conventionally.

Finally, research has shown that parents use a number of different reading styles when sharing books with their children (Shapiro et al., 1997). The way of reading to the child in this study was representative of what Reese and Cox (1999) named a "performance-oriented" style in which the story is read from beginning to end with little interruption. Other reading styles might be more effective in promoting attention to the print. For example, Reese and Cox observed that a "describer style" with breaks that focused on describing elements of the illustrations during reading re- 
sulted in more development of 4-year-olds' print-related skills over a 6-week period than did a "performance" or "comprehender" style with breaks about story meaning. However, this finding was complicated by the fact that children's initial levels of comprehension also played a role in which style was most effective. It might be noted that Aram (2006), in a study with lower socioeconomic status children ages 3 to 5 , also found that storybook intervention resulted in improved letter knowledge only in the older children. It had no effect on word writing or letter retrieval over a control condition.

\section{GENERAL SUMMARY AND CONCLUSIONS}

Consistent with prior research (de Jong \& Bus, 2002; Evans \& Saint-Aubin, 2005; Justice et al., 2005; Yaden et al., 1993), it is clear that children attend much more to the illustrations than the print when an adult is reading storybooks to them. Even at 5 years of age, when children can identify many letters of the alphabet and understand that letters in words are arranged linearly, evenly spaced, with uppercase letters only at the beginning of word, storybook reading appears to be more of a listening activity while looking at the pictures than a time to explore print. This finding illuminates why little or no direct correlation between the frequency of shared book reading in the home and the development of print skills has emerged in previous studies (Evans et al., 2000; Frijters et al., 2000; Levy et al., 2006; Sénéchal et al., 1998; van Kleeck, 1998). Although it is unclear how much attention to the text in informal contexts is necessary for a child to learn and remember its visual form (but see Apel et al., 2006), the total amount of time looking toward the printed pages was roughly just $6 \mathrm{sec}$ for each book in the standard condition. Therefore, if one of the goals of shared reading is to enhance print skills and orthographic knowledge, our results suggest that parents should choose genres of books that increase attention to and spontaneous conversation about print, such as alphabet books, and/or engage in specific behaviors to increase the amount of attention paid to print during storybook reading.

This study also suggested that pointing to the words while reading to the child may be one parental behavior that increases children's attention to print during shared reading. Although the potential benefits of it on children's print knowledge or their own pointing to the words while looking at/reading books alone (Pierce, 2000 , as cited in Stahl, 2003) were not addressed here, pointing to the print did increase the amount of time that children at all three ages looked toward the printed page and affected 4-year-olds' ability to recall the print targets. As such it may be an effective procedure for helping children to match print to sound, especially if they have a preliminary awareness of phonemes and some letters that represent them (Ehri \& Sweet, 1991; Uhry, 1999). 
Finally, it should be noted that a primary goal of shared book reading for children in this age group in many cases may not be to enhance print specific knowledge but for general cognitive development or enjoyment and entertainment. Activities outside of shared book reading, specifically adult mediated printing and writing activities have been shown to substantially enhance print knowledge (e.g., Aram \& Levin, 2004) and would be valuable print specific adjuncts to shared book reading for fostering attention to and memory for print.

\section{ACKNOWLEDGMENTS}

Karen Williamson has graduated and is now at the Halton District Board of Education. Tiffany Pursoo has graduated and is now at the University of Ottawa. Grateful appreciation is extended to the Canadian Language and Literacy Research Network for funding this research and to the participating preschools and children. Part of this research was presented at the biennial meeting of the Society for Research in Child Development, Atlanta, April 2005.

\section{REFERENCES}

Adams, M. J. (1990). Beginning to read. Cambridge, MA: MIT Press.

Apel, K., Wolter, J. A., \& Masterson, J. J. (2006). Effects of phototactic and orthotactic probabilities during fast-mapping on a 5-year-olds' learning to spell. Developmental Neuropsychology, 29, 21-42.

Aram, D. (2006). Early literacy interventions: The relative roles of storybook reading, alphabetic activities, and their combination. Reading and Writing, 19, 489-515.

Aram, D., \& Levin, I. (2004). The role of maternal mediation of writing to kindergarteners in promoting literacy in school: A longitudinal perspective. Reading and Writing, 17, 387-409.

Baker, L., Mackler, K., Sonnenschein, S., \& Serpell, R. (2001). Parents' interactions with their first-grade children during storybook reading and relations with subsequent home reading activity and reading achievement. Journal of School Psychology, 39, 415-438.

Bus, A. G., van IJzendoorn, M. H., \& Pellegrini, A. D. (1995). Joint book reading makes for success in learning to read: A meta-analysis on intergenerational transmission of literacy. Review of Educational Research, 65, 1-21.

de Jong, M. T., \& Bus, A. G. (2002). Quality of book-reading matters for emergent readers: An experiment with the same book in a regular or electronic format. Journal of Educational Psychology, 94, $145-155$.

Dunn, L. M., \& Dunn, L. M. (1997). Peabody Picture Vocabulary Test-III. Circle Pines, MN: American Guidance Services.

Ehri, L., \& Sweet, J. (1991). Finger-point reading of memorized text: What enables beginners to process the print? Reading Research Quarterly, 26, 442-462.

Elliot, C. D. (1983). British Abilities Scales. Windsor, UK: NFER-Nelson.

Evans, M. A., Levy, B. A., \& Jared, D. (2001). Home Literacy Experiences Questionnaire. [Available from M. A. Evans, Department of Psychology, University of Guelph, Guelph, Ontario, Canada N1G 2W1]

Evans, M. A., \& Saint-Aubin, J. (2005). What children are looking at during shared storybook reading. Psychological Science, 16, 913-920. 
Evans, M. A., Shaw, D., \& Bell, M. (2000). Home literacy activities and their influence on early literacy skills. Canadian Journal of Experimental Psychology, 54, 65-75.

Ezell, H., \& Justice, L. M. (1998). A pilot investigation of parent questions about print and pictures to preschoolers with language delay. Child Language Teaching and Therapy, 14, 273-278.

Ezell, H. K., \& Justice, L. M. (2000). Encouraging the print focus of shared reading sessions through observational learning. American Journal of Speech-Language Pathology, 9, 36-47.

Foulin, J. N. (2005). Why is letter-name knowledge such a good predictor of learning to read? Reading and Writing, 18, 129-155.

Frijters, J. C., Barron, R. W., \& Brunello, M. (2000). Direct and mediated influences of home literacy and literacy interest on pre-readers' oral vocabulary and early written language skill. Journal of Educational Psychology, 92, 466-477.

Golden, J., \& Gerber, A. (1990). A semiotic perspective of text: The picture book story event. Journal of Reading Behavior, 22(3), 203-219.

Hiebert, E. H. (1981). Developmental patterns and interrelationships of preschool children's print awareness. Reading Research Quarterly, 16, 236-259.

Howell, D. C. (1997). Statistical methods for psychology: Fourth edition. Toronto: Duxbury.

Justice, L. M., \& Ezell, H. K. (2000). Enhancing children's print and word awareness through home-based parent intervention. Child Language Teaching and Therapy,_9, 257-269.

Justice, L. M., \& Ezell, H. K. (2002). Use of storybook reading to increase print awareness in at-risk children. American Journal of Speech-Language Pathology, 11, 17-29.

Justice, L. M., Skibbe, L., Canning, A., \& Lankford, C. (2005). Preschoolers, print and storybooks: An observational study using eye movement analysis. Journal of Research in Reading, 28, 229-243.

Justice, L. M., Weber, S. E., Ezell, H. K., \& Bakeman, R. (2002). A sequential analysis of children's responsiveness to parental print references during shared book-reading interactions. American Journal of Speech-Language Pathology, 11, 30-40.

Levy, B. A., Gong, Z., Hessels, S., Evans, M. A., \& Jared, D. (2006). Understanding print: early reading development and the contributions of home literacy experiences. Journal of Experimental Child Psychology, 93, 63-93.

Lomax, R. G., \& McGee, L. M. (1987). Young children's concepts about print and reading: Toward a model of word reading acquisition. Reading Research Quarterly, 22, 237-256.

Maestro, B., \& Maestro, G. (1981). Harriet reads signs and more signs. New York: Crown.

Mason, J. M. (1980). When do children begin to read: An exploration of four-year-old children's letter and word reading competencies. Reading Research Quarterly, 15, 203-227.

Nicoll, H., \& Pienkowski, J. (1972). Meg and Mog. London: Puffin.

Phillips, G., \& McNaughton, S. (1990). The practice of storybook reading to preschool children in mainstream New Zealand families. Reading Research Quarterly, 25, 196-212.

Reese, E., \& Cox, A. (1999). Quality of adult book reading affects children's emergent literacy. Developmental Psychology, 35, 20-28.

Roberts, W. L. (2003). FOCAL32: Program for the collection and analyses of observational data. Available from http://www.cariboo.bc.ca/ae/psych/faculty/roberts/homepage.htm

Scarborough, H. S., \& Dobrich, W. (1994). On the efficacy of reading to preschoolers. Developmental Review, 14, 245-302.

Sénéchal, M., LeFevre, J, Thomas, E., \& Daley, K. (1998). Differential effects of home literacy experiences on the development of oral and written language. Reading Research Quarterly, 32, 96-116.

Shapiro, J., Anderson, J., \& Anderson, A. (1997). Diversity in parental storybook reading. Early Child Development and Care, 127-128, 47-59.

Stahl, S. A. (2003). What do we expect storybook reading to do? How storybook reading impacts word recognition. In A. van Kleeck, S. A. Stahl, \& E. B. Bauer (Eds.), On reading books to children: Parents and teachers (pp. 363-383). Mahwah, NJ: Lawrence Erlbaum Associates. 
Statistics Canada. (2001a). Median family income in constant (2000) dollars for all census families and both spouses or partners with earnings, for Canada, provinces, territories, and census subdivisions (Municipalities) with 5,000-population-20\% sample data. Retrieved September 25, 2003, from http://www.statscan.ca/english/census01/products/highlight/Income/PrintFriendly

Statistics Canada. (2001b). Population 15 years and over by highest level of schooling, provinces and territories. Retrieved September 25, 2003, from http://www.statcan.ca/english/Pgdb/educ43b.htm

Tabachnick, B. G., \& Fidell, L. S. (1996). Using multivariate statistics (3rd ed.). New York: Harper Collins College.

Uhry, J. K. (1999). Invented spelling in kindergarten: The relationship with finger-point reading. Reading and Writing: An Interdisciplinary Journal, 11, 441-464.

van Kleeck, A. (1995). Emphasizing form and meaning separately in prereading and early reading instruction. Topics in Language Disorders, 16, 27-49.

van Kleeck, A. (1998). Preliteracy domains and stages: Laying the foundations for beginning reading. Journal of Children's Communication Development, 20, 33-51.

van Kleeck, A. (2003). Research on book sharing: Another critical look. In A. van Kleeck, S. A. Stahl, \& E. B. Bauer (Eds.), On reading books to children: Parents and teachers (pp. 271-320). Mahwah, NJ: Lawrence Erlbaum Associates.

Wechsler, D. (1991). Wechsler Intelligence Scale for Children-Third Edition. San Antonio, TX: Psychological Corporation.

Woodcock, R. W., McGrew, K. S., \& Manther, N. (2001). The Woodcock-Johnson III. Itasca, IL: Riverside.

Yaden, D. B., Jr., Smolkin, L. B., \& Conlon, A. (1993). Preschoolers' questions about pictures, print convention, and story text during reading aloud at home. Reading Research Quarterly, 24, 189-214. 
Copyright of Scientific Studies of Reading is the property of Lawrence Erlbaum Associates and its content may not be copied or emailed to multiple sites or posted to a listserv without the copyright holder's express written permission. However, users may print, download, or email articles for individual use. 